\title{
Masseter Muscle
}

National Cancer Institute

\section{Source}

National Cancer Institute. Masseter Muscle. NCI Thesaurus. Code C13074.

A muscle of mastication originating from the zygomatic arch. 